\title{
Disparity between recent graduates' and experienced surgeons' assessment of time to operative independence
}

\author{
Dawn S. Hui, MD, ${ }^{\text {a }}$ Richard Lee, MD, MBA, ${ }^{a}$ Marc R. Moon, MD, ${ }^{b}$ Melanie A. Edwards, MD, ${ }^{c}$
} Mina L. Boutrous, MD, ${ }^{\mathrm{c}}$ Jessica G. Y. Luc, BMedSc, ${ }^{\mathrm{d}}$ Richard L. Prager, MD, ${ }^{\mathrm{e}}$ and Keith S. Naunheim, MD

\section{ABSTRACT}

Background: In cardiothoracic surgery, little data exist on the transition to operative independence. We aimed to compare current perceptions of operative autonomy of junior cardiothoracic surgeons and senior colleagues who oversee transitional years.

Methods: An anonymous online survey was sent to currently practicing North American board-certified/eligible cardiothoracic surgeons to assess reported time to operative independence and comfort with cardiothoracic operations. The $\chi 2$ test, Fisher exact test, and Mann-Whitney $U$ test were used to compare junior surgeons' self-reported experience to the junior experience as reported by the midcareer and senior surgeons with whom they practiced. Logistic regression was performed to assess factors associated with operative independence.

Results: Responses from 436 completed surveys were analyzed (82 juniors and 354 midcareer/seniors). Two hundred fifty-four midcareer/senior surgeons reported on the experience of 531 junior partners. Juniors reported high immediate posttraining comfort with basic cardiac cases and moderate comfort with all other categories. Time to operative independence was significantly different between juniors' self-report and midcareer/senior reports of junior partners except for complex thoracic cases. In multivariable logistic regression analysis, senior, and not midcareer, surgeon status was independently associated with junior operative independence status for cardiac cases and for basic thoracic cases.

Conclusions: Most junior surgeons perceived operative independence with basic thoracic, basic cardiac, and complex cardiac operations earlier in their surgical career than that reported by senior colleagues. Objective measures of operative independence may clarify this discrepancy. This study establishes a baseline by which to compare the effects of integrated 6-year programs on operative independence. The discrepant perceptions may have implications for how training programs prepare graduates for the transition to independent practice. (J Thorac Cardiovasc Surg 2019;157:1925-32)

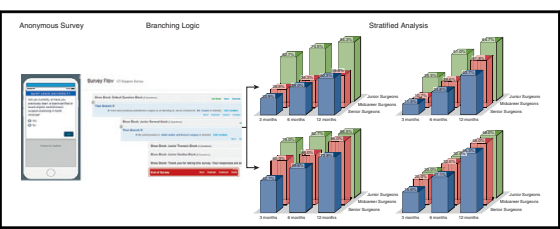

Time to junior operative autonomy is differently reported by practicing junior surgeons and midcareer/ senior surgeons who oversee practicing junior surgeons.

\section{Central Message}

The current junior surgeon experience of transitioning to operative autonomy is differently reported by practicing junior surgeons and midcareer/senior surgeons who oversee practicing junior surgeons.

\section{Perspective}

Perceptions and experiences of junior surgeon readiness for operative autonomy differ between less and more experienced surgeons. This may influence junior surgeons' early career success, including outcomes and patient safety. The residency training years may be an opportunity to better align expectations. Future studies should incorporate objective meaningful measures such as risk-adjusted outcomes.

See Commentary page 1933.

\footnotetext{
From the ${ }^{\mathrm{a} C e n t e r}$ for Comprehensive Cardiovascular Care, and ${ }^{\mathrm{c}}$ Division of Vascular Surgery, Department of Surgery, Saint Louis University, Saint Louis, Mo; ${ }^{\mathrm{b}}$ Division of Cardiothoracic Surgery, Washington University School of Medicine, Barnes-Jewish Hospital, Saint Louis, Mo; ${ }^{\mathrm{d}}$ Division of Cardiac Surgery, University of Alberta, Edmonton, Alberta, Canada; and ${ }^{\mathrm{e}}$ Department of Cardiac Surgery, University of Michigan, Ann Arbor, Mich.

Read at the 98th Annual Meeting of The American Association for Thoracic Surgery, San Diego, California, April 28-May 1, 2018.

Received for publication March 20, 2018; revisions received Aug 25, 2018; accepted for publication Aug 27, 2018; available ahead of print Dec 12, 2018.

Address for reprints: Dawn S. Hui, MD, Center for Comprehensive Cardiovascular Care, 3635 Vista Ave, DT 13th Fl, Saint Louis, MO 63110 (E-mail: dawn.hui@ health.slu.edu).

$0022-5223 / \$ 36.00$

Copyright (c) 2018 by The American Association for Thoracic Surgery

https://doi.org/10.1016/j.jtcvs.2018.08.124
}

Cardiothoracic surgery is a discipline that requires 10 to 12 years of postgraduate training. Even after this lengthy preparation, recent graduates are rarely fully expert or equipped to safely perform complex operations independently and often spend additional years under the tutelage

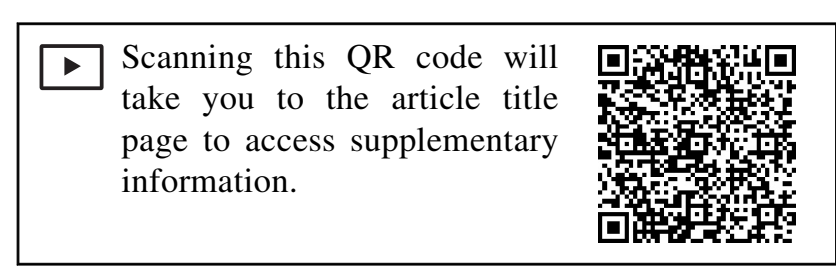




\section{Abbreviations and Acronyms \\ $\mathrm{CABG}=$ coronary artery bypass grafting \\ $\mathrm{I}-6=$ integrated 6-year training program}

of a senior surgeon, particularly for complex cases. A number of studies have documented the perceptions and comfort levels of resident physicians or recent graduates with regard to their technical skills abilities and competency. ${ }^{1,2}$ However, little data exist on how trainees transition to independence during the initial posttraining years. Further, recent trends such as increasing emphasis on minimally invasive and endovascular technical training have decreased the number of open cases performed by trainees that may also affect preparation for these transitional years. A recent longitudinal study showed an increase in the proportion of resident physicians intending to pursue additional training ${ }^{3}$ that may be related to these trends. Therefore, we aimed to study the perceptions and comfort levels of cardiothoracic surgeons during their junior years (ie, 5 years or less since completion of an accredited cardiothoracic surgery residency program) as well as the perceptions of the senior colleagues who oversee their transitional years.

\section{MATERIALS AND METHODS (VIDEO 1) Study Population}

The Cardiothoracic Surgery Network directory was used to generate a list of cardiothoracic surgeons in North America. All practicing adult cardiothoracic surgeons in the United States and Canada were eligible for inclusion. The directory was reviewed in combination with an Internet search engine to identify and exclude surgeons who were not actively practicing adult cardiac or thoracic surgery, were retired, or deceased. The list of recent graduates was augmented with the Thoracic

\section{Disparity between recent graduates and experienced surgeons' assessment of time to operative independence}

Dawn S. Hui, Richard Lee, Marc A. Moon, Melanie A. Edwards, Mina L. Boutrous, Jessica GY Luc, Richard L. Prager, Keith S. Naunheim

1 May 2018

$98^{\text {th }}$ Annual Meeting of the

American Association of Thoracic Surgeons San Diego, CA

VIDEO 1. Survey development and design. Video available at: https:// www.jtcvs.org/article/S0022-5223(18)32925-8/fulltext.
Surgery Directors' Association e-mail list of graduates between 2010 and 2016

\section{Survey Tool}

A survey tool (Online Data Supplement) consisting of multiple-choice and text entry items was developed by the principal investigators (DH, $\mathrm{RL}, \mathrm{ME}$, and $\mathrm{KN}$ ) in a multistep process of question and format design, several iterations of internal review and revision, and finally external feedback solicited from 3 other board-certified actively practicing cardiothoracic surgeons. The survey design consisted of a multiblock set of questions, categorized first based on junior versus midcareer or senior status, then by practice type (cardiothoracic, cardiac, or thoracic). The first set of questions included demographic characteristic questions regarding the cardiothoracic surgeon's practice type, the number and seniority of practice partners, and his or her first job duration. Question blocks were then subdivided by surgeon experience and type of practice (Figure 1, middle). Junior surgeons were asked to grade their immediate posttraining comfort level with basic and complex procedures on a 5 -point Likert scale $(1=$ not comfortable and $5=$ completely comfortable) and time interval from graduation to operative independence. Senior surgeons were queried on the demographic characteristics of their 3 most recent junior partners and the time interval to operative independence of these junior partners. Beta-testing was conducted by members of the research team to ensure appropriate flow.

Throughout the survey, the following definitions were used: junior surgeons were those who had completed training $<5$ years ago, midcareer surgeons were those who had completed training 5 to 9 years ago, and senior surgeons were those who had completed training 10 or more years ago. Operative independence was defined as "operating without senior surgeon assistance; ie, not scrubbed in and serving as first assistant." For basic and complex cases, the following examples were given in the survey questions: basic thoracic (wedge resection, lobectomy, decortication), complex thoracic (esophagectomy, sleeve lobectomy, completion pneumonectomy), basic cardiac (straightforward coronary artery bypass grafting [CABG] with normal ejection fraction and good targets, isolated valve replacement), complex cardiac (complex CABG, porcelain aorta, diabetic target vessels, aortic dissections, CABG plus valve). Group size was calculated by summing the number of senior, midcareer, and junior partners in the respondent's practice group.

\section{Survey Distribution and Statistical Analysis}

Recruitment was through e-mail messages sent from 2 of the authors ( $\mathrm{RL}$ and $\mathrm{KN}$ ) containing a link to an anonymous online survey (Online Data Supplement) that was accessible by desktop or mobile smartphone (Figure 1, left). The survey was sent in batches, with an initial date of June 6, 2017, 1 reminder e-mail message, and discontinuation of survey link access on July 1, 2017. A total of 4969 survey invitations were sent of which 486 invalid e-mail returns were received.

Survey responses were collected using the Qualtrics Survey Software (Provo, Utah). Analysis was conducted with IBM-SPSS Statistics for Windows, version 25.0 (IBM-SPSS Inc, Armonk, NY). The outcomes of junior operative independence at 3,6 , and 12 months in the 4 case categories (basic and complex cardiac, basic and complex thoracic) were compared between groups using Pearson $\chi^{2}$ analysis. Groups were compared using $\chi^{2}$ analysis (or Fisher exact test when any cell count $<5$ ) for categorical variables and Mann-Whitney $U$ test for continuous variables, which did not follow the normal distribution as assessed by Kolgorov-Smirnov $(P<.001$ for all continuous variables). Four univariable analyses were performed on the outcomes of operative independence at 3 months for basic operations and at 12 months for complex operations for cardiac and thoracic operations. Multivariable logistic regression was then performed using significant univariable factors. For all analyses, 2 -sided tail with a $P$ value significance level $<.05$ was used. The study was approved by 


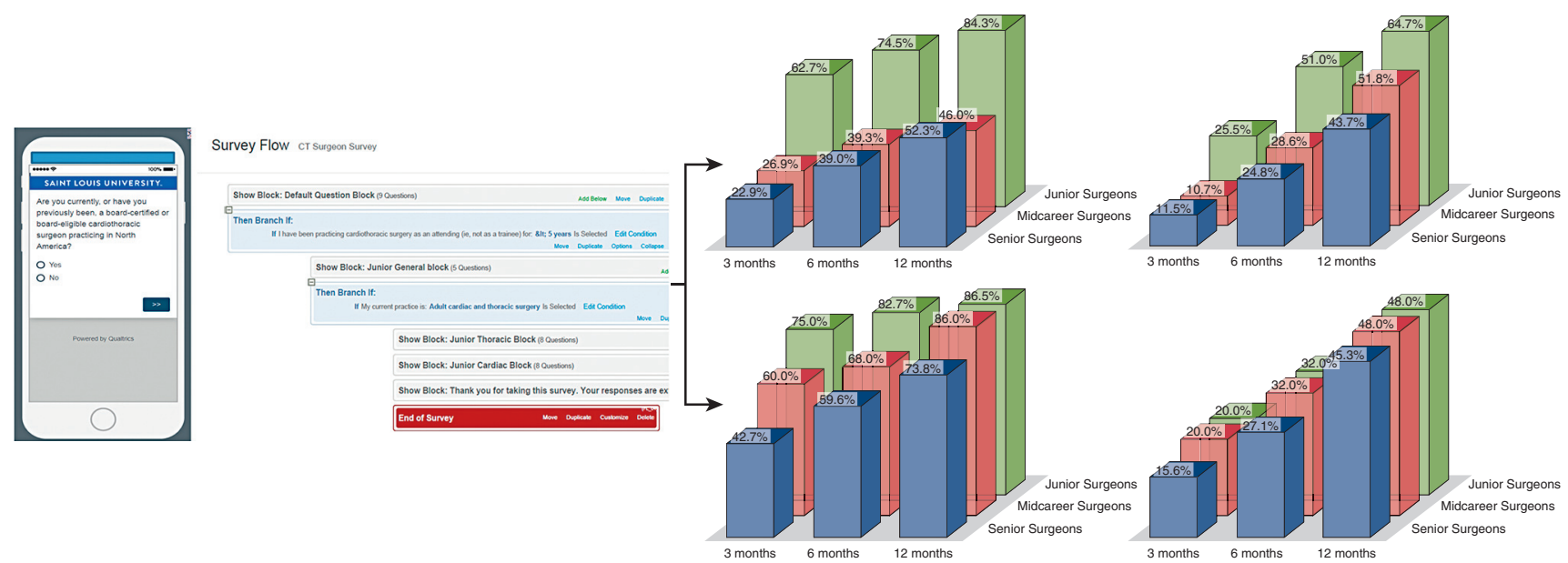

FIGURE 1. Study design. Left, An online link to an anonymous survey accessible by desktop or mobile device was sent to Cardiothoracic Surgery Network members. Middle, Survey flow employed branching logic according to time since training and practice domain. Right, Separate univariable analyses were performed for cardiac and thoracic practices, comparing the 3 cohorts by seniority.

the Saint Louis University Institutional Review Board (protocol No. 27368).

\section{RESULTS}

The survey link was accessed 539 times for a response rate of $12 \%$ for valid e-mail addresses. Responses from individuals who identified as not board-certified/eligible $(n=36)$, retired $(n=18)$, primarily congenital practice $(n=9)$, or other disciplines (ie, administrative, vascular, or critical care) $(\mathrm{n}=10)$ were excluded (total excluded $=73)$.
Of the remaining 466 respondents, $17.6 \%(\mathrm{n}=82)$ were junior surgeons, $12.4 \%(\mathrm{n}=58)$ were midcareer surgeons, $63.5 \%(n=296)$ were senior surgeons, and 6.4\% $(n=30)$ did not respond to the question regarding their seniority status. This last category was excluded from further analysis. The characteristics of respondents is presented in Table 1. The training reported by most junior respondents' training was a standard curriculum consisting of 5 years of general surgery training plus cardiothoracic training of 2 years' $(41.5 \% ; \mathrm{n}=34)$ or 3 years' $(4.9 \% ; \mathrm{n}=4)$ duration.

\section{TABLE 1. Characteristics of all respondents}

\begin{tabular}{|c|c|c|c|}
\hline Characteristic & Junior surgeons $(n=82)$ & $\begin{array}{l}\text { Midcareer and senior } \\
\text { surgeons }(n=354)\end{array}$ & $P$ value \\
\hline \multicolumn{4}{|l|}{ Practice type } \\
\hline Adult cardiac and thoracic & $28.0(23)$ & $36.7(130)$ & \\
\hline Adult cardiac & $34.1(28)$ & $29.7(105)$ & .504 \\
\hline Adult thoracic & $35.4(29)$ & 30.8 (109) & \\
\hline Other & $2.4(2)$ & $2.8(10)$ & \\
\hline \multicolumn{4}{|l|}{ Practice environment } \\
\hline Private, hospital-based & $23.2(19)$ & $37.0(131)$ & \\
\hline Private, group practice & $9.8(8)$ & $16.4(58)$ & $<.001^{*}$ \\
\hline Academic & $50.0(41)$ & $41.2(146)$ & \\
\hline Government & $9.8(8)$ & $2.0(7)$ & \\
\hline Other & $7.3(6)$ & $3.4(12)$ & \\
\hline Private practice & $32.9(27)$ & $53.4(189)$ & $<.001^{*}$ \\
\hline \multicolumn{4}{|l|}{ Practice group characteristics } \\
\hline Number of total surgeons & $5.00(3.00-7.00)$ & $4.00(2.00-8.00)$ & .196 \\
\hline Number of senior surgeons & $2.00(1.00-4.00)$ & $2.00(1.00-5.00)$ & .877 \\
\hline Number of midcareer surgeons & $0.00(0.00-1.00)$ & $1.00(0.00-2.00)$ & .132 \\
\hline Number of junior surgeons & $1.00(1.00-2.00)$ & $0.00(0.00-1.00)$ & $<.001^{*}$ \\
\hline
\end{tabular}

Values are presented as $\%$ (n) or median (interquartile range). $* P<.05$ 
More than half had no additional training time, whereas one-fifth spent 7 to 12 months in additional training. The practice environment was academic or government in $59.8 \%$ and private in $29.2 \%$. Of the $32.9 \%$ who reported having changed jobs within the first 5 years, the median time spent in their first position was 2.00 years (interquartile range [IQR], 2-3 years).

Of the midcareer and senior surgeons, $72 \%(\mathrm{n}=254)$ reported on their junior partners' operative independence. When comparing the demographic profiles of the junior respondents to as the junior partners of the responding midcareer/senior surgeons, the junior respondents were less likely to be in private practice $(32.9 \%$ vs $46.9 \% ; P=.018)$ and more likely to have undergone a standard curriculum $(P<.001)$.

\section{Comfort Level: Junior Surgeons}

Junior surgeons' self-reported comfort levels immediately after training for basic and complex cases is shown in Table 2. Comfort with both basic and complex thoracic cases was moderate, whereas comfort with cardiac cases was high for basic operations and moderate for complex operations.

Of the 53 junior surgeons who performed thoracic operations, $92.5 \%(\mathrm{n}=49)$ reported currently operating independently for basic operations, the majority doing so within 3 months of training completion $(75.5 \% ; n=40)$. Slightly more than half reported operating independently for complex operations $(52.8 \% ; n=28)$, with one-third doing so within 6 months of training completion. Of those who had not achieved independence with complex operations, $42.8 \%(\mathrm{n}=9)$ expected to do so within 1 year of training; $19 \%(\mathrm{n}=4)$ expected to do so between 12 and 18 months.

Of the 52 junior surgeons who performed cardiac operations, $86.5 \%(n=45)$ reported independently operating for basic operations, with $63.5 \%$ doing so within 3 months of training and $75 \%$ by 6 months. Reported independence with complex operations was also high at $73.1 \%$, with

TABLE 2. Comfort level posttraining

\begin{tabular}{ll}
\hline \multicolumn{1}{c}{ Operation type } & Comfort level \\
\hline Thoracic $(\mathrm{n}=49)$ & \\
Lobectomy & $4.00(400-5.00)$ \\
Esophagectomy & $3.00(2.00-4.00)$ \\
Complex thoracic & $3.00(2.00-4.000)$ \\
Cardiac $(\mathrm{n}=46)$ & \\
Straightforward coronary artery bypass grafting & $5.00(4.00-5.00)$ \\
Isolated valve & $5.00(4.00-5.00)$ \\
Acute aortic dissection & $4.00(2.00-5.00)$ \\
Complex coronary bypass grafting & $3.00(2.00-4.00)$ \\
Complex valve & $3.00(2.00-4.00)$ \\
\hline
\end{tabular}

Respondents used a Likert scale, where $1=$ not comfortable and $5=$ completely comfortable. Values are presented as median (interquartile range).
$25 \%$ reporting independence within 3 months and 50\% by 6 months.

\section{Time to Operative Independence: Comparison of Junior and Senior Reporting}

The time to operative independence was reported at significantly earlier time points by junior surgeons, compared with the junior surgeon experience as reported by supervising midcareer and senior surgeons for basic thoracic, basic cardiac, and complex cardiac cases, with the exception of basic thoracic cases at 12 months, where junior and midcareer surgeons reported differently than the senior cohort. There was no significant difference for complex thoracic cases (Table 3 and Figures 2 and 3). Multivariable logistic regression analysis showed that senior surgeon status differed significantly from junior and midcareer surgeon status in reporting junior operative independence for basic thoracic cases at 3 months, basic cardiac cases at 3 months, and complex cardiac cases at 12 months. Group size was predictive for basic and complex cardiac cases. Midcareer surgeon status was also predictive of operative independence for basic cardiac cases. Unadjusted and adjusted odds ratios are shown in Table 4.

\section{Effect of Additional Training}

Amongst junior surgeons engaged in thoracic surgery, $38.5 \%$ had completed additional training, whereas $47 \%$ of cardiac surgeons had completed additional training. Univariable analysis shows that this was the only significant predictor of juniors reporting operative independence for basic cases at 3 months and complex cases at 12 months, with the exception of traditional training also predicting independence for complex cardiac cases (Table 5). However, it should be noted that the confidence interval is quite wide suggesting that a larger sample size is needed.

\section{Wave Analysis}

Due to the low response rate, a wave analysis was performed, using the date June 22, 2017, to define the cutoff between early and late survey responders. Among juniors, group differences were not significant for practice type, environment, or group size. Using Fisher exact test, comfort level and time to operative independence did not differ between early and late responders for cardiac or thoracic procedures. Among midcareer and senior surgeons, late responders had larger practice group sizes (median, 6.0; IQR, 3.0-10.0 vs median, 4.0; IQR, 2.0-8.0). The only statistically significant difference between early and late responders was in the categories of basic thoracic at 3 months and complex thoracic at 3 and 6 months, with late responders more likely to report earlier junior operative independence. 
TABLE 3. Time to operative independence by operation type

\begin{tabular}{|c|c|c|c|c|}
\hline $\begin{array}{c}\text { Time to junior } \\
\text { surgeon operative } \\
\text { independence (mo) }\end{array}$ & $\begin{array}{c}\text { Reported by } \\
\text { junior surgeons }\end{array}$ & $\begin{array}{c}\text { Reported by } \\
\text { midcareer partners }\end{array}$ & $\begin{array}{c}\text { Reported by } \\
\text { senior partners }\end{array}$ & $P$ value \\
\hline \multicolumn{5}{|c|}{ Basic thoracic operation } \\
\hline 3 & $75(39)$ & $60.0(30)$ & $42.7(96)$ & $<.001 *$ \\
\hline 6 & $82.7(43)$ & $68.0(34)$ & $59.6(134)$ & $.006^{*}$ \\
\hline 12 & $86.5(45)$ & $86.0(43)$ & $73.8(166)$ & $.042 *$ \\
\hline \multicolumn{5}{|c|}{ Complex thoracic operation } \\
\hline 3 & $23.1(12)$ & $20.0(10)$ & $15.6(35)$ & .381 \\
\hline 6 & $34.6(18)$ & $32.0(16)$ & $27.1(61)$ & .496 \\
\hline 12 & $44.2(23)$ & $48.0(24)$ & $45.3(102)$ & .922 \\
\hline \multicolumn{5}{|c|}{ Basic cardiac operation } \\
\hline 3 & $62.7(32)$ & $26.8(15)$ & $22.9(74)$ & $<.01 *$ \\
\hline 6 & $74.5(38)$ & $39.3(22)$ & $39.0(126)$ & $<.01 *$ \\
\hline 12 & $84.3(43)$ & $46.4(26)$ & $52.3(169)$ & $<.01^{*}$ \\
\hline \multicolumn{5}{|c|}{ Complex cardiac operation } \\
\hline 3 & $25.5(13)$ & $10.7(6)$ & $11.5(37)$ & $.019^{*}$ \\
\hline 6 & $51.0(26)$ & $28.6(16)$ & $24.8(80)$ & $.001^{*}$ \\
\hline 12 & $64.7(33)$ & $51.8(29)$ & $43.7(141)$ & $.015^{*}$ \\
\hline
\end{tabular}

Values are presented as $\%$ (n). *Two-tailed $P<.05$.

\section{DISCUSSION}

In 2002, a pivotal survey was administered to graduating residents by the Thoracic Surgery Residents Association that identified low rates of satisfaction with the job search process and thoracic surgery board exam preparation in addition to career dissatisfaction in nearly a quarter of respondents. ${ }^{4}$ However, in addition to those disappointing results, the survey showed that $97 \%$ of resident physicians reported having been adequately trained and prepared for operative activities. The survey presented here is the first to attempt to critically assess the metric of operative preparedness after residency by comparing the self-reported experiences of juniors with the perceptions of midcareer and senior surgeons who oversee junior partners in practice. There are a few trends that may help explain this change.
First, during the past 15 years there has been an ongoing increase in technology, which means resident physicians have more to learn both outside and within the operating room. New technology as well as novel operative procedures must first be mastered by faculty before they can be taught; thus, the caseload available for resident physician training may be limited by such innovation. In addition, many procedures once done via a limited number of approaches are now done via a wide range of approaches, including thoracoscopic, endoscopic, laparoscopic, robotic, and endovascular approaches. These many approaches fragment the operative caseload into smaller numbers of various operations. This can slow or even prevent the acquisition of the critical case volume necessary to consider oneself competent. Performing 30 open lobectomies leaves one
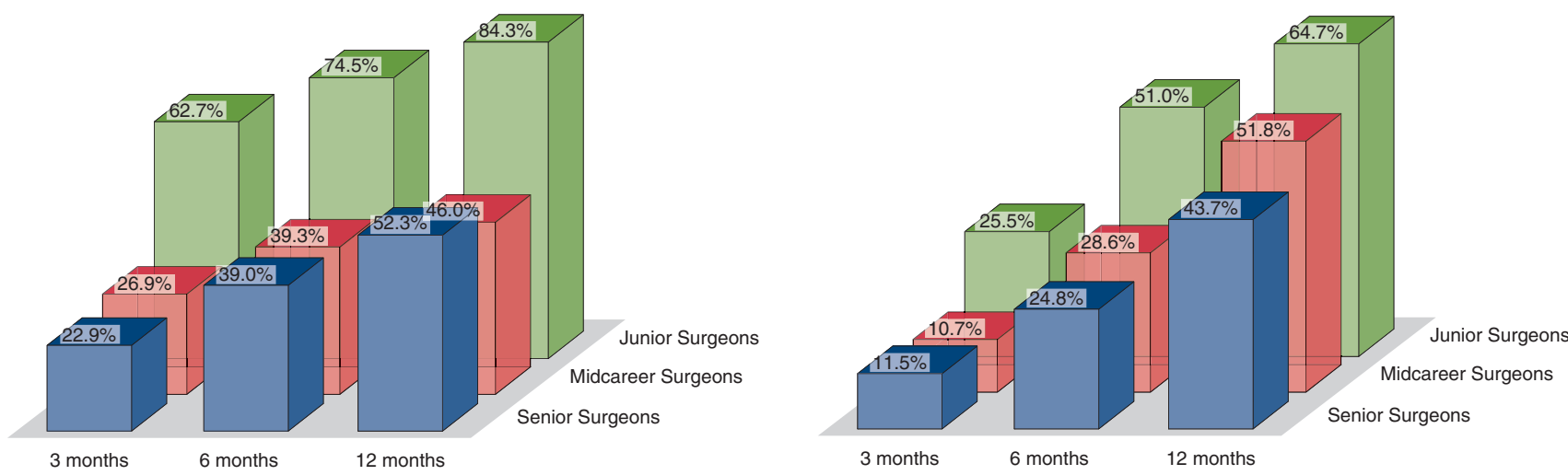

FIGURE 2. Time to junior operative autonomy as reported by junior surgeons (green bars), midcareer surgeons (red bars), and senior surgeons (blue bars). Left, Basic cardiac surgery skills. Right, Complex cardiac skills. 

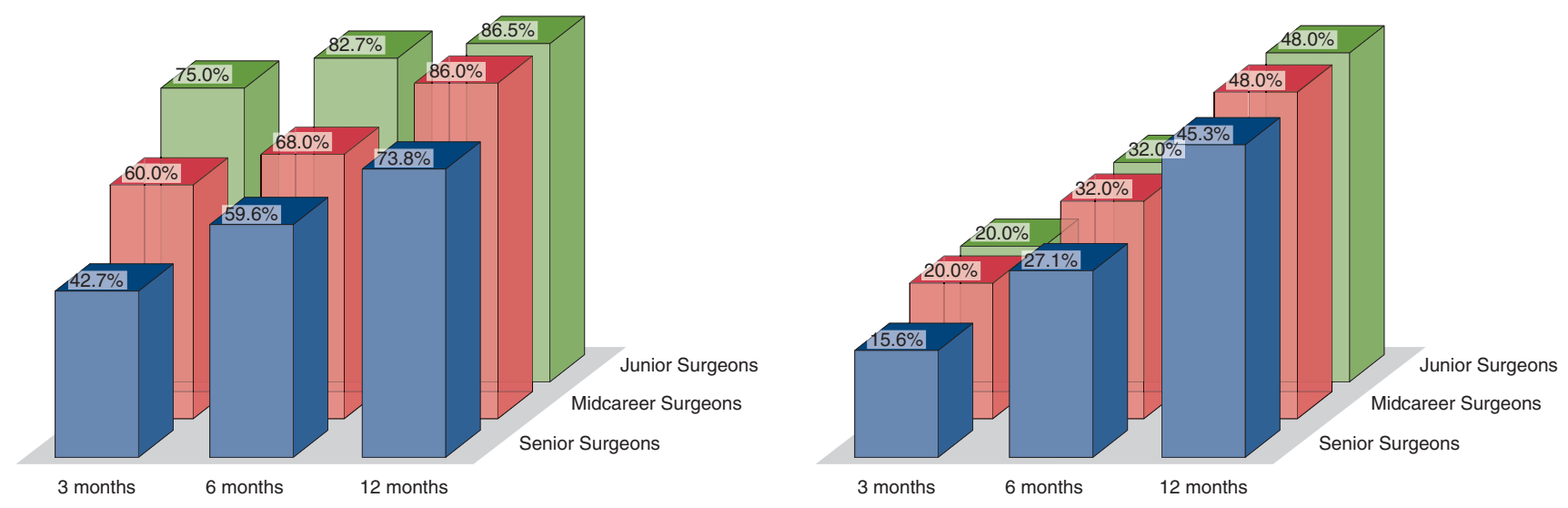

FIGURE 3. Time to junior operative autonomy as reported by junior surgeons (green bars), midcareer surgeons (red bars), and senior surgeons (blue bars). Left, Basic thoracic surgery skills. Right, Complex thoracic surgery skills.

TABLE 4. Logistic regression analysis of junior operative independence

\begin{tabular}{|c|c|c|c|c|c|c|}
\hline & $\begin{array}{l}\text { Unadjusted } \\
\text { odds ratio }\end{array}$ & $\begin{array}{l}95 \% \text { Confidence } \\
\text { interval }\end{array}$ & $P$ value & $\begin{array}{l}\text { Adjusted } \\
\text { odds ratio }\end{array}$ & $\begin{array}{l}95 \% \text { Confidence } \\
\text { interval }\end{array}$ & $P$ value \\
\hline \multicolumn{7}{|c|}{ Basic thoracic independence at $3 \mathrm{mo}^{*}$} \\
\hline \multicolumn{7}{|c|}{ Surgeon seniority } \\
\hline \multicolumn{7}{|l|}{ Junior, reference } \\
\hline Midcareer & 4.031 & $2.040-7.965$ & $<.001 \dagger$ & 0.458 & $0.193-1.088$ & .077 \\
\hline Senior & 2.016 & $1.079-3.764$ & $.028 \dagger$ & 0.246 & $0.123-0.492$ & $<.001 \dagger$ \\
\hline Group size & 1.049 & $1.001-1.100$ & $.046 \dagger$ & 1.040 & $0.988-1.095$ & .135 \\
\hline Private practice & 0.560 & $0.362-0.869$ & $.010^{\dagger}$ & 0.708 & $0.433-1.158$ & .169 \\
\hline Training structure $\ddagger$ & 0.888 & $0.526-1.499$ & .656 & & & \\
\hline \multicolumn{7}{|c|}{ Basic cardiac independence at 3 mo $\S$} \\
\hline \multicolumn{7}{|c|}{ Surgeon seniority } \\
\hline \multicolumn{7}{|l|}{ Junior, reference } \\
\hline Midcareer & 0.217 & $0.096-0.493$ & $<.001 \dagger$ & 0.194 & $0.083-0.454$ & $<.001 \dagger$ \\
\hline Senior & 0.176 & $0.095-0.329$ & $<.001 \dagger$ & 0.168 & $0.086-0.329$ & $<.001 \dagger$ \\
\hline Group size & 1.075 & $1.032-1.119$ & $<.001 \dagger$ & 1.088 & $1.037-1.141$ & $.001 \dagger$ \\
\hline Private practice & 0.581 & $0.379-0.891$ & $.013 \dagger$ & 0.915 & $0.547-1.531$ & .735 \\
\hline Training structure $\ddagger$ & 0.550 & $0.345-0.877$ & $.012 \dagger$ & 0.784 & $0.459-1.339$ & .373 \\
\hline \multicolumn{7}{|c|}{ Complex thoracic independence at $12 \mathrm{mo}$} \\
\hline \multicolumn{7}{|l|}{ Surgeon seniority } \\
\hline \multicolumn{7}{|l|}{ Junior, reference } \\
\hline Midcareer & 1.164 & $0.534-2.537$ & .703 & & & \\
\hline Senior & 1.046 & $0.570-1.918$ & .886 & & & \\
\hline Group size & 1.013 & $0.970-1.058$ & .563 & & & \\
\hline Private practice & 0.918 & $0.594-1.419$ & .701 & & & \\
\hline Training structure $\ddagger$ & 0.918 & $0.543-1.551$ & .749 & & & \\
\hline \multicolumn{7}{|c|}{ Complex cardiac independence at $12 \mathrm{mo} \|$} \\
\hline \multicolumn{7}{|c|}{ Surgeon seniority } \\
\hline \multicolumn{7}{|l|}{ Junior, reference } \\
\hline Midcareer & 0.586 & $0.269-1.275$ & .178 & 0.517 & $0.235-1.138$ & .101 \\
\hline Senior & 0.423 & $0.228-0.782$ & $.006 \dagger$ & 0.385 & $0.207-0.717$ & $.003 \dagger$ \\
\hline Group size & 1.074 & $1.031-1.119$ & $.001 \dagger$ & 1.078 & $1.035-1.124$ & $<.001 \dagger$ \\
\hline Private practice & 0.712 & $0.487-1.041$ & .080 & & & \\
\hline Training structure $\ddagger$ & 0.820 & $0.529-1.272$ & .375 & & & \\
\hline
\end{tabular}

*Model $\chi^{2},<0.001$; Nagelkerke $R^{2}, 0.107 . \dagger P<.05$. †Dichotomized as traditional versus other. §Model $\chi^{2}<0.001 ;$ Nagelkerke $R^{2}, 0.155$. $\|$ Model $\chi^{2},<0.001 ;$ Nagelkerke $R^{2}$, 0.068 . 
TABLE 5. Logistic regression analysis of junior surgeons only

\begin{tabular}{|c|c|c|c|}
\hline & $\begin{array}{l}\text { Unadjusted } \\
\text { odds ratio }\end{array}$ & $\begin{array}{c}95 \% \text { Confidence } \\
\text { interval }\end{array}$ & $P$ value \\
\hline \multicolumn{4}{|l|}{ Basic thoracic $3 \mathrm{mo}$} \\
\hline Group size & 1.014 & $0.822-1.251$ & .895 \\
\hline Private practice & 1.000 & $0.275-3.634$ & 1.000 \\
\hline Training structure* & 1.684 & $0.467-6.068$ & .425 \\
\hline Additional training & 9.667 & $2.207-42.334$ & $.003 \dagger$ \\
\hline \multicolumn{4}{|c|}{ Complex thoracic $12 \mathrm{mo}$} \\
\hline Group size & 1.147 & 0.941-1.399 & .174 \\
\hline Private practice & 1.052 & $0.342-3.238$ & .930 \\
\hline Training structure ${ }^{*}$ & 0.718 & $0.239-2.157$ & .555 \\
\hline Additional training & 3.857 & $1.128-13.192$ & $.031 \dagger$ \\
\hline \multicolumn{4}{|l|}{ Basic cardiac 3 mo } \\
\hline Group size & 1.164 & $0.953-1.421$ & .137 \\
\hline Private practice & 1.513 & $0.473-4.836$ & .485 \\
\hline Training structure* & 1.685 & $0.511-5.557$ & .391 \\
\hline Additional training & 4.136 & $1.232-13.893$ & $.022 \dagger$ \\
\hline \multicolumn{4}{|l|}{ Complex cardiac 12 mo } \\
\hline Group size & 1.237 & $0.990-1.545$ & .061 \\
\hline Private practice & 2.762 & $0.802-9.516$ & .107 \\
\hline Training structure* & 5.312 & $1.290-21.872$ & $.021 \dagger$ \\
\hline Additional training & 3.500 & $1.044-11.734$ & $.042 \dagger$ \\
\hline
\end{tabular}

*Dichotomized as traditional versus other. $\nmid$ Two-tailed $P<.05$.

fairly confident that one can do a lobectomy, but if instead those cases are apportioned into open and thoracic robotic procedures, a trainee may not do enough of any single type to attain a level of comfort.

Yet another factor may be the trend towards transparency with publicly available outcomes reporting. Senior surgeons may now be more attuned to the scrutiny of their operative results, and thus may not hand down as many cases as is optimal, especially if the cases are complex. This scrutiny might also hinder faculty from providing trainees any meaningful autonomous activity. This latter hypothesis is supported by a recent survey on autonomy evaluation that utilized real-life cases. In the report, both trainees and their supervising attending physicians had higher expectations for autonomy than was observed across a spectrum of cases. ${ }^{4}$ The influence of the integrated 6-year programs will be an area of future study. Ward and colleagues ${ }^{5}$ found that compared with traditional pathways, integrated 6-year training programs (I-6) had more time dedicated to general thoracic rotations than other nonsurgical rotations. However, the effect of this differing balance of training components on preparedness for surgery is unknown at this time. In the first nationwide survey of I-6 program directors, 75\% believed their I-6 graduates would be able to independently perform routine cardiac and thoracic operations by the time of graduation, with this rate increasing to $86 \%$ in mature programs. ${ }^{6}$ Sixty-seven percent believed I-6 graduates would be "better trained" than traditional pathways, although this was not specific to operative preparedness.

The significant differences reported here suggest that there may be an opportunity to better align expectations between new graduates and the senior colleagues who hire them. At the very least, practice groups might benefit from a prospective effort to adjust the expectations of junior and the senior surgeons who hire them. In addition, senior surgeons could design and implement a structured transition to independent practice. This would consist of an identified period of 1-on-1 mentorship both in and out of the operating room with gradual assimilation of clinical responsibility by the junior surgeon over a 6- to 12-month period. Ideally this would culminate in the production of a fully confident and independent practitioner, without undue risk to patients or anxiety on the part of the either junior or senior surgeon.

Finally, although the nonadjusted odds ratio shows midcareer and senior surgeons skewing differently from junior surgeons (Figure 1, right), multivariable analysis showed that senior, and not midcareer, surgeon status was significantly associated with a difference in the assessment of time to operative independence for basic thoracic and complex cardiac cases. Both midcareer and senior surgeon status was significant for basic cardiac cases. This raises the question of whether there is a difference in expectations among senior and midcareer surgeons or a difference in the training paradigm that has evolved over a decade. Further research will be needed to explore these questions.

\section{Limitations}

The first limitation relates to study design. Limited guidance and lack of consensus exist in the field of survey reporting. ${ }^{7}$ As with any voluntary survey study, a common limitation is nonresponse bias. Attempts to limit this bias included incorporation of response facilitation approaches as outlined by Rogelberg and Scranton. ${ }^{8}$ Due to the anonymity of the survey, junior and midcareer/senior respondents may have come from disparate practices leading to selection bias. Junior respondents who are confident in their operative independence may have been more likely to respond, whereas senior surgeons who perceive that junior transition to independence is an ongoing problem may have spurred selection in the opposite direction. Although comments cannot be analyzed as a representative sample, 12 of 42 senior comments were negative regarding the current state or personal experience with junior preparedness, 3 were positive, and 5 expressed that factors other than technical ability were responsible for problems with transition, including lack of business/financial skills, decreasing volume, lack of hospital support, and leadership deficiency.

We also note that the response rate of $12 \%$ needs to be interpreted with caution. The denominator for this response rate was the number of e-mail addresses of all potential actively practicing cardiothoracic surgeons identified in 
Cardiothoracic Surgery Network. The true denominator of interest, for the midcareer and senior surgeon group, would be those who have accepted a junior partner into their practice during the past 5 to 7 years. Based on the number of graduates from the Thoracic Surgery Directors' Association e-mail list, we believe the relevant response rate is in fact closer to $85 \%$ to $90 \%$. In accordance with published bias assessment techniques, follow-up approach and wave analysis techniques were used. ${ }^{8}$ Wave analysis suggested no significant bias in the junior cohort or cardiac cohorts. However, amongst senior thoracic respondents, late responders were more likely to report earlier operative independence in basic and complex thoracic cases at 3 months and complex thoracic cases at 6 months. This is intriguing because complex thoracic was the only category to show nonsignificant differences in time to operative independence when comparing junior and senior reports. Optimal techniques to address nonresponse rates and bias remain an area of controversy ${ }^{9}$; in fact, a recent comprehensive analysis of published health professions trainee surveys found that none evaluated for nonresponse bias. ${ }^{10}$ More data in the specific area of cardiothoracic surgery training are needed to apply other techniques such as archival and benchmarking analyses.

Another limitation is the lack of certain objective data. In trying to obtain a balance between survey length and maximizing the complete response rate, some details were purposely excluded. In particular, thoracic questions were deliberately nonspecific as to the operative approach (thoracotomy vs minimally invasive or robotic). The study was not designed to be a referendum on the learning curve of these various approaches but on the surgeon comfort whatever their preferred approach. Further, if a skew were to exist, we would expect it to be in the opposite direction of the results; that is, we would expect senior surgeons to be biased toward thoracotomy approach and junior surgeons towards minimally invasive approaches, which are known to have a greater learning curve. However, this is conjecture at this stage, and the influence of operative approach on operative independence is another area for future study.

Finally, the reliability and validity of this survey have not been assessed. Due to the lack of comparable prior studies, it was developed de novo based on the authors' experience as practicing surgeons and educators at academic centers and thus may have been biased toward an academic center experience. The range of time since training completion of the survey developers ranged from 5 to 32 years.

To explore the factors underlying the findings of this survey, future studies in this area would be strengthened by the inclusion of objective data such as in-training case volumes, the time interval from training completion to board certification, and perhaps even the inclusion of operative results. After all, the ultimate outcome of interest is not merely surgeon perceptions but patient safety and outcomes. Review of risk-adjusted Society of Thoracic Surgeons outcomes data might in the future prove useful to validate the disparate perceptions recorded here, and to provide a benchmark against which to judge these perceptions. Finally, it has been suggested that that independent observers of procedure video recordings can be valuable to assess expertise and competency, and using such an approach could provide objective data that might help minimize subjective biases such as selection and recall.

\section{CONCLUSIONS}

Most junior surgeons perceive operative independence with basic thoracic and both basic and complex cardiac operations early in their surgical careers. This perception differed significantly from the reporting by midcareer and senior surgeons of their current junior partners. Perhaps this is merely a subjective gap in perception of time to independence that can never be filled, although as surgeons we recognize the importance of experience-especially after we have it. More objective measures of operative independence may clarify this discrepancy and illuminate areas for intervention.

\section{Conflict of Interest Statement}

Authors have nothing to disclose with regard to commercial support.

The authors thank Dr Fernando Fleischman, Dr Alex Brescia, and Dr Faiz Bhora for evaluating the survey and Dr Paula Buchanan for providing statistical analysis assistance.

\section{References}

1. Chu D, Vaporciyan AA, Iannettoni MD, Ikonomidis JS, Odell DD, Shemin RJ, et al. Are there gaps in current thoracic surgery residency training programs? Ann Thorac Surg. 2016;101:2350-5.

2. Odell DD, Macke RA, Tchantchaleishvili V, Loor G, Nelson JS, LaPar DJ, et al. Resident perception of technical skills education and preparation for independent practice. Ann Thorac Surg. 2015;100:2305-12.

3. Stephens EH, Odell D, Stein W, LaPar DJ, DeNino WF, Aftab M, et al. A decade of change: training and career paths of cardiothoracic surgery residents 2003 to 2014. Ann Thorac Surg. 2015;100:1305-13.

4. Lee R. Help wanted. Ann Thorac Surg. 2003;76:1779-81.

5. Ward ST, Smith D, Andrei AC, Hicks GL Jr, Shemin RJ, Calhoon JH, et al. Comparison of cardiothoracic training curricula: integrated six-year versus traditional programs. Ann Thorac Surg. 2013;95:2051-4.

6. Lebastchi AH, Tackett JJ, Argenziano M, Calhoon JH, Gasparri MG, Halkos ME, et al. First nationwide survey of US integrated 6-year cardiothoracic surgical residency program directors. J Thorac Cardiovasc Surg. 2014;148:408-15.e401.

7. Bennett C, Khangura S, Brehaut JC, Graham ID, Moher D, Potter BK, et al. Reporting guidelines for survey research: an analysis of published guidance and reporting practices. PLoS Med. 2010;8:e1001069.

8. Rogelberg SG, Stanton JM. Introduction: understanding and dealing with organizational survey nonresponse. Organiz Res Methods. 2016;10:195-209.

9. Peress M. Correcting for survey nonresponse using variable response propensity. J Am Stat Assoc. 2010;105:1418-30.

10. Phillips AW, Friedman BT, Utrankar A, Ta AQ, Reddy ST, Durning SJ. Surveys of health professions trainees. Acad Med. 2017;92:222-8.

Key Words: cardiothoracic surgery, surgical education, education research 